\section{Polymerization Shrinkage of Bulk Fill Composites and its Correlation with Bond Strength}

Lauber Jose dos Santos Almeida Junior'1, Estevam Carlos de Oliveira Lula², Karla Janilee de Souza Penha' ${ }^{1}$ Vinicius Souza Correia', Fernando Augusto Cintra Magalhães ${ }^{3,4}$, Darlon Martins Lima', Leily Macedo Firoozmand ${ }^{1}$

\begin{abstract}
The present study aimed to evaluates polymerization shrinkage (PS) using microcomputed tomography $(\mu \mathrm{CT})$ and microtensile bond strength ( $\mu \mathrm{TBS})$ in bulk fill composites (BFC) and conventional class I restorations as well as the correlation between these factors. Class I cavities ( $4 \times 5 \times 4 \mathrm{~mm})$, factor- $\mathrm{C}=4.2$, were created in third molars that were free of caries, which were randomly divided in 4 groups $(n=6)$ : XTI (Filtek Supreme XTE: incremental technique); XTB (Filtek Supreme XTE: single fill technique); TBF (Tetric Bulk Fill); and SF (SonicFill). Each tooth was scanned twice in $\mu \mathrm{CT}$ : T0 was after filling the cavity with composite, and T1 was after light curing. The data were analyzed by subtracting the composite volume for each time (T1 - T0). After 1 week, the teeth were sectioned crosswise in the buccolingual and mesiodistal directions to obtain specimens with approximately $1 \mathrm{~mm}^{2}$ thickness and fixed in a universal testing machine to perform $\mu T B S$. The Kruskal-Wallis and Dunn tests showed a statistically significant difference for shrinkage in $\mu \mathrm{CT}$ among the XTI and XTB and between the SF and XTB. Regarding the $\mu T B S$, all the groups differed from XTB. Bulk fill composites type presents a PS similar to that of the conventional nanoparticulate composite inserted using the incremental technique, but the bond strength was higher for the incremental group, which presented a lower number of pre-test failures when compared to BFC. No correlation was observed between the polymerization shrinkage and bond strength in the studied composites.
\end{abstract}

'Department of Dentistry 1, UFMA - Universidade Federal do Maranhão, São Luís, MA, Brasil 2Program in Public Health, UFMA - Universidade Federal do Maranhão, São Luís, MA, Brasil ${ }^{3}$ Department of Physiology and Pathology, Araraquara Dental School, UNESP - Universidade Estadual Paulista, Araraquara, SP, Brazil ${ }^{4}$ Department of Pathology, Nursing School, UFMA - Universidade Federal do Maranhão, Imperatriz, MA, Brasil

Correspondence: Lauber Jose dos Santos Almeida Junior, Universidade Federal do Maranhão, Centro de Ciências Biológicas e da Saúde, Departamento de Odontologia 1. Campus Bacanga, 65085580, São Luís, MA, Brasil. Tel: +55-98-98804-3207. e-mail: lauberjunior@hotmail.com

Key Words: polymerization, $x$-ray microtomography, composite resins, tensile strength

\section{Introduction}

Modifications in the organic matrix of composites have allowed for the evolution of new materials known as bulk fill composites (BFCs). These materials have been indicated for use in a single layer in deep cavities ( 4 to $5 \mathrm{~mm}$ ) and with a high-factor cavity configuration (Factor-C), simplifying the steps in the clinic (1). Some studies have shown that BFCs have presented adequate marginal adaptation (2), low polymerization shrinkage (1) and satisfactory results in bond strength $(3,4)$.

Even with the development of new polymeric materials, polymerization shrinkage (PS) of composites is an unavoidable phenomenon because it is an inherent property of these materials. There is significant evidence that the stress of PS in the composites can lead to deleterious effects, such as marginal leakage, gap formation, cuspal deflection, tooth cracking, reduced resin-dentin bond strength, and lowered mechanical properties, which cause great concern about the control of these effects and make the phenomenon clinically relevant (5).

The most obvious concern with respect to the PS stresses is the detrimental effect on marginal integrity and sealing of the composite restoration to the tooth (5), which may lead to tooth/composites interface failure, but these failures can be minimized by performing the incremental insertion technique, with the decrease of the C-factor (4).

It is known that the fill technique and the type of composite can have a great impact on adhesion, particularly in cavities with high C-factor (6). However, the methods used to observe cavity filling and marginal adaptation require the samples to be subjected cuts that generate severe stress, causing changes and the formation of small cracks and creeps (7). In light this, some questions about the fidelity of the observed results, regarding whether these failures occur before or after the PS or if the failures occur during filling of the cavity. Another question is whether the failures, the PS, and inadequate filling could interfere with the bond strength of the restoration. Within this context, recent the microcomputed tomography $(\mu \mathrm{CT})$ has been presented in the literature (7-9) as a safe and nondestructive method of analyzing a material's behavior in 3D without deteriorating or destroying the specimens (10).

When considering cavity-filling techniques with composites, increased shrinkage tension is of a great relevance and may present negative effects on resindentin bond strength (11). There is a shortage of studies that evaluate by means of correlation analysis if the 
polymerization shrinkage is associated with the bond strength, therefore, to affirm this correlation without observing images before and after the polymerization raises doubts about the adaptation at the interface of the pulp wall.

Using non-destructive (microcomputed tomography$\mu \mathrm{CT}$ ) and destructible (microtensile bond strength- $\mu \mathrm{TBS}$ ) tests, the aim of this in vitro study was to analyze the PS and resin-dentin bond strength of class I restorations with high C-factor, with different bulk fill composites and a conventional composite, to correlate these factors with each other. The null hypotheses tested were that: (I) there is no difference in the volume of polymerization shrinkage of bulk fill and conventional composites; (II) there is no difference in $\mu \mathrm{TBS}$ between bulk fill and conventional composites; and (III) there is no correlation between PS in $\mu \mathrm{CT}$ and $\mu \mathrm{TBS}$ between these composites.

\section{Material and Methods}

This study was submitted to the Research Ethics Committee in Brazil and approved under number 1708531.

Sample Preparation

One-way ANOVA was used to determine the sample size, considering 4 groups. From the data obtained by Fronza et al. (12) for inter-group variance (147.2) the intra-group variance (104.8), a sample size of 4 units per group was obtained for an alpha of 5\% and power of $80 \%$.

Twenty-four caries-free third molars were cleaned and stored in thymol at $0.5 \%$, followed by prophylaxis and storage in distilled water at $37^{\circ} \mathrm{C} \pm 1^{\circ} \mathrm{C}$ for $24 \mathrm{~h}$.

Standard Class I cavities of $4 \mathrm{~mm}$ deep ( $4 \times 5 \times 4 \mathrm{~mm}$ - Fig. 1) and with high $\mathrm{C}$-factor $(\mathrm{C}=4.2)$ were made with diamond tips no. 1090 and 1014 (KG SORENSEN, Cotia, $\mathrm{SP}$, Brazil) at high-rotation refrigeration. The live internal angles were plumped (2) to make the force dissipation and adaptation of the material easier. The prepared teeth were randomly divided in 4 experimental groups $(n=6)$, according to the composites used for restoration of the cavities (Table 1): XTI (Filtek Supreme XTE: incremental technique); XTB (Filtek Supreme XTE: bulk fill technique); TBF (Tetric Bulk Fill, insertion according the manufacturer's instruction); and SF (SonicFill, insertion according the manufacturer's instructions). The restorative materials and their respective information and filling/insertion techniques are described in Table 1.

\section{Restorative Procedure}

After sample preparation, the cavities were conditioned with 37\% phosphoric acid (FGM, Joinville, Brazil), then washed with water and the excess was removed with absorbent paper, followed by application of the adhesive system Single Bond 2 (3M, ESPE, St. Paul, MN, USA) according to the manufacturer's instructions, and polymerized for 10 s. The composite was inserted according to Table 1 for each group, and the condensation was performed with a cosmedent SP2 spatula (Cosmedent, Chicago, IL, USA); after, the composites were light cured for $40 \mathrm{~s}$. During the restorative procedure to avoid any light sources, the samples were immediately protected in dark plastic vials and placed in the apparatus microtomography chamber for a scan and volume quantification before light curing. In the microtomography chamber, there was no light incidence once the operational protocol for $\mu$ CT Skyscan 1176 (Skyscan, Kontich, Antwerp, Belgium) takes place in a dark environment. All of the polymerization procedures were performed with light cured with a high-power LED light-curing device (Bluephase, Ivoclar Vivadent; Schaan, Liechtenstein) with an output above $1100 \mathrm{~mW} / \mathrm{cm} 2$ for $40 \mathrm{~s}$ (13). The same operator performed all the restorative procedures. Then, the specimens were stored in distilled water at $37^{\circ} \mathrm{C} \pm 1^{\circ} \mathrm{C}$ for $24 \mathrm{~h}$.

\section{$\mu C T$ Scanning and Analysis}

Images were obtained using microtomography SkyScan 1176. A computerized microtomograph was used to analyze the restored cavities. Each tooth was scanned in two times: T0- after the insertion of the resin composite and T1-after

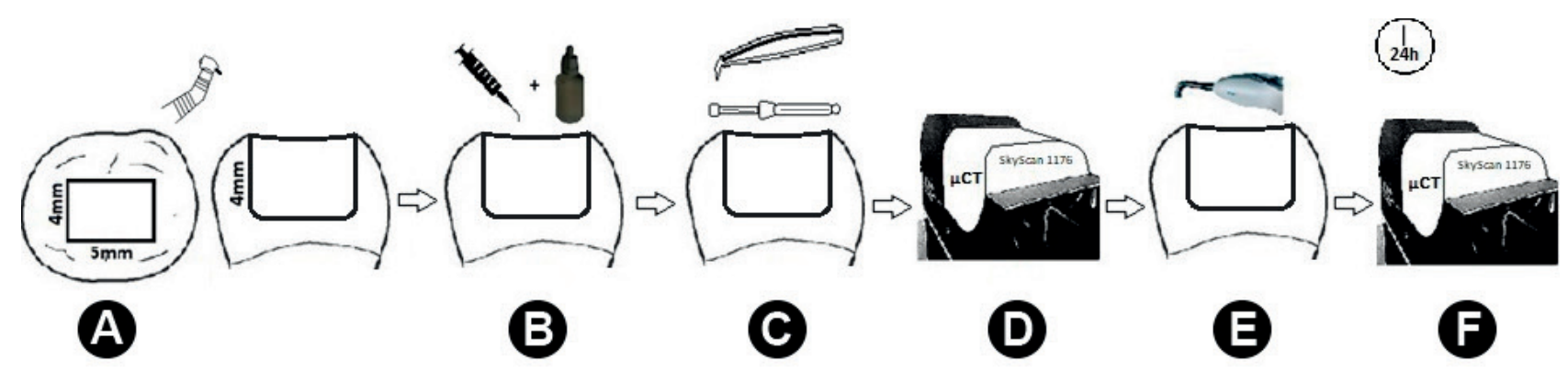

Figure 1. Figure representative of sample preparation and scanning. Cavity preparation (A), Cavity acid etching and bonding (B), Cavity filling with the composite resins (C), First scan (D), Light curing (E), Second scan after $24 \mathrm{~h}$ of light curing (F). 
the final polymerization (Fig. 2). The microtomograph acted under the operating condition for the power device (90 Kvp, 275 microamperes) with a resolution of $17.48 \mu \mathrm{m}$ (filter $\mathrm{Cu}=0.1 \mathrm{~mm}$ ). The jig that was used was the one of the own machine. The average of the total number of slices was 250, with an average reading time close to 28 minutes. The images were standardized in the DataViewer ${ }^{\circledR}$ software and the analyses were performed in CTAnalyser ${ }^{\circledR}$. All the calculations were performed on the volume of interest (VOI) obtained from the region of interest (ROI) centered on the delimitations of restorative material. The volumetric analyses aimed to quantify the resin composite volume at two different moments. The initial reading (TO) was considered "reference," and the final reading (T1) was considered a "target" in order to align the images geometrically. From these measures, the volume of the polymerization shrinkage was calculated in percentage through analysis of the anatomical structure of the restoration. The final shrinkage volume was measured by the difference between the times and expressed as a percentage.

\section{Microtensile Bond Strength ( $\mu$ TBS)}

After 1 week of storage in distilled water at 37

Table 1. Technique and compositions of Materials Investigated

\begin{tabular}{|c|c|c|c|c|}
\hline $\begin{array}{l}\text { Material } \\
\text { (Group) }\end{array}$ & Manufacturer & Composition & $\begin{array}{c}\text { Increment } \\
\text { size }\end{array}$ & $\begin{array}{l}\text { Insertion } \\
\text { technique }\end{array}$ \\
\hline $\begin{array}{l}\text { Filtek Supreme XTE } \\
\text { (XTI) }\end{array}$ & $\begin{array}{l}\text { 3M ESPE, } \\
\text { St. Paul, } \\
\text { MN, USA }\end{array}$ & $\begin{array}{l}\text { Non-agglomerated silica nanoparticles (20nm), non- } \\
\text { agglomerated zirconia (4 to } 11 \mathrm{~nm}) .78 .5 \mathrm{wt} \% \text { and } 63.3 \mathrm{vol} \% \text {. } \\
\text { Matrix: Bis-GMA UDMA, TEGDMA, PEGDMA and bis-EMA }\end{array}$ & $1.5 \mathrm{~mm}$ & $\mathrm{IT} / \mathrm{MI}$ \\
\hline $\begin{array}{l}\text { Filtek Supreme XTE } \\
\text { (XTB) }\end{array}$ & $\begin{array}{l}\text { 3M ESPE, } \\
\text { St. Paul, } \\
\text { MN, USA }\end{array}$ & $\begin{array}{l}\text { Non-agglomerated silica nanoparticles ( } 20 \mathrm{~nm} \text { ), non- } \\
\text { agglomerated zirconia (4 to } 11 \mathrm{~nm}) .78 .5 \mathrm{wt} \% \text { and } 63.3 \mathrm{vol} \% \text {. } \\
\text { Matrix: Bis-GMA UDMA, TEGDMA, PEGDMA and bis-EMA }\end{array}$ & $4 \mathrm{~mm}$ & $\mathrm{BT} / \mathrm{MI}$ \\
\hline $\begin{array}{l}\text { Tetric Bulk Fill } \\
\text { (TBF) }\end{array}$ & $\begin{array}{c}\text { Ivoclar } \\
\text { Vivadent, } \\
\text { Schaan, } \\
\text { Liechtenstein, } \\
\text { GE }\end{array}$ & $\begin{array}{l}\text { Barium aluminium silicate glass with two different mean } \\
\text { particle sizes, an „Isofiller“, ytterbium fluoride and spherical } \\
\text { mixed oxide, ivocerin initiator, 79-81 wt } \%, 61 \text { vol\% and } \\
\text { 17vol\% “Isofillers”. Matrix: Bis-GMA, Bis-EMA, UDMA }\end{array}$ & $4 \mathrm{~mm}$ & $\mathrm{BT} / \mathrm{MI}$ \\
\hline $\begin{array}{l}\text { SonicFill } \\
\text { (SF) }\end{array}$ & $\begin{array}{l}\text { Kerr, Orange, } \\
\text { CA, USA }\end{array}$ & $\begin{array}{l}\text { Barium glass, silicon dioxide (5-10\%), oxide, chemicals } \\
\text { (10-30\%), MPS (10-30\%), silicon dioxide, EBPDMA ( } 1- \\
\text { 5\%), bisphenol A bis (2-hydroxy-3-methacryloxypropyl) } \\
\text { ether (1-5\%), and TEGDMA (1-5\%) (Filler } 83.5 \mathrm{wt} \%)\end{array}$ & $4 \mathrm{~mm}$ & $\mathrm{BT} / \mathrm{SI}$ \\
\hline $\begin{array}{l}\text { Adper Single } \\
\text { bond } 2 \\
\text { (etch-and-rinse } \\
\text { adhesive system) }\end{array}$ & $\begin{array}{l}\text { 3M ESPE, } \\
\text { St. Paul, } \\
\text { MN, USA }\end{array}$ & $\begin{array}{l}\text { Bis-GMA, HEMA, dimethacrylates, photoiniciator, } \\
\text { methacrylate functional copolymer of polyacrylic and } \\
\text { polyitaconic acids, } 10 \% \text { by weight of } 5 \text { nanometer- } \\
\text { diameter spherical silica particles, water, ethanol. }\end{array}$ & \multicolumn{2}{|c|}{$\begin{array}{l}\text { Apply two consecutive coats of } \\
\text { adhesive to the tooth surface with } \\
\text { gentle agitation for } 15 \mathrm{~s} \text {; gently } \\
\text { air thin; light cure for } 10 \mathrm{~s}\end{array}$} \\
\hline
\end{tabular}

Bis-EMA: Bisphenol-A polyethylene glycol diether dimethacrylate; Bis-GMA: Bisphenol-A diglycidyl ether dimethacrylate; EBPDMA: Ethoxylated Bisphenol-A-dimethacrylate; TEGDMA: Triethylene glycol dimethacrylate; PEGDMA: polyethylene glycol dimethacrylate; UDMA: Urethane dimethacrylate, MPS: 3-(trimethoxysilyl) propyl methacrylate; HEMA: 2-Hydroxyethyl methacrylate. IT: incremental technique; BT: bulk fill technique; MI: manual insertion; SI: sonic insertion.
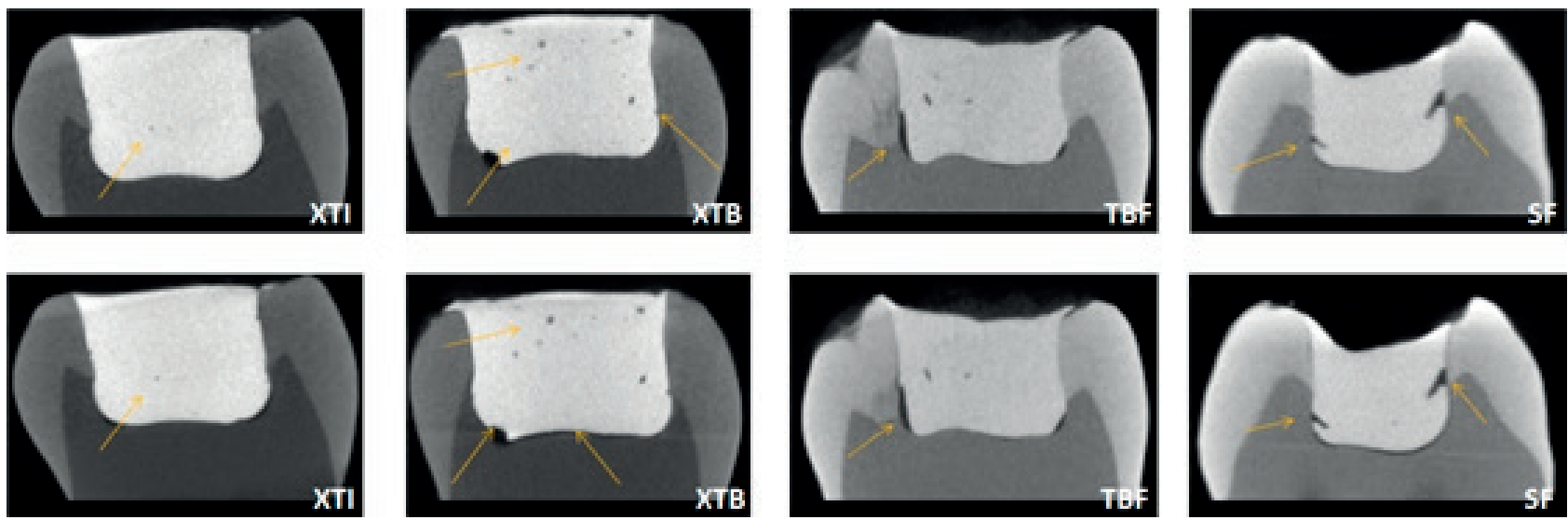

Figure 2. Cavity filling with composite before (upper) and after (lower) curing, respectively. Presence of gaps and voids evidenced by the arrows. XTI (Filtek Supreme XTE: incremental technique); XTB (Filtek Supreme XTE: single fill technique); TBF (Tetric Bulk Fill); SF (SonicFill). 
${ }^{\circ} \mathrm{C} \pm 1{ }^{\circ} \mathrm{C}$, the teeth were perpendiculary sectioned in the buccolingual and mesiodistal directions to obtain specimens with approximately $1 \mathrm{~mm}^{2}$ thickness in serial cuts. The cross-sectional measurement was performed using a digital caliper (Mitutoyo Co., Tokyo, Japan). The specimens were fixed to a Geraldeli 1 -jig at their ends with ethyl cyanoacrylate-based glue (Atascadero, CA, USA) in a microtensile device coupled to a universal testing machine (INSTRON Equipment and Test systems Ltda., São José dos Pinhais, PR, Brazil). A speed of $1 \mathrm{~mm} / \mathrm{min}$ was employed until the specimens fractured. The bond strength was expressed in megapascals (MPa), calculated by the ratio between the applied force $(\mathrm{N})$ at the moment of fracture and the exposed area (A) $\left(\mathrm{mm}^{2}\right)$.

The type of failure was observed using a 50x magnification optical microscope (PanTec, Panambra Ind., and Technique AS, São Paulo, Brazil) and classified into 3 types: A (adhesive failure), $C$ (cohesive failure in the composite or dentin), and $\mathrm{M}$ (mixed failure).

\section{Statistical Analysis}

The Shapiro-Wilk test indicated that the polymerization shrinkage values and bond strength did not show normal distributions. The data were analyzed using a Kruskal-Wallis test followed by a Dunn posthoc test for $p<0.05$. The correlation between the bond strength and the volume shrinkage was obtained using Spearman's rank correlation coefficient $(p<0.05)$. The statistical software STATA 14 (College Station, TX, USA) was used for the data analysis.

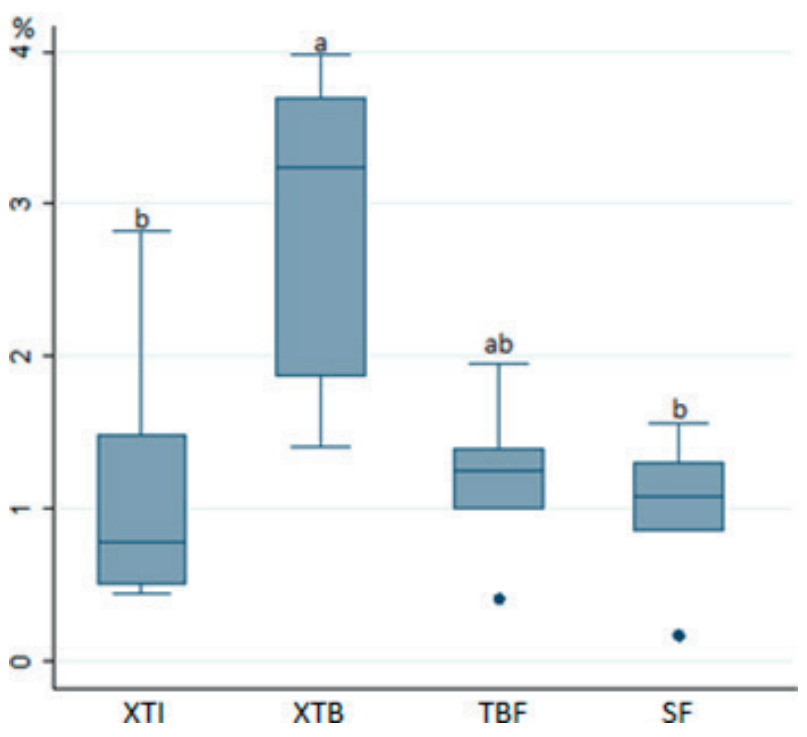

Figure 3. Boxplot of the volumetric polymerization shrinkage in $\mu \mathrm{CT}$. Groups with the same letter are not statistically significantly different ( $p>0.05)$. VS: volumetric shrinkage; XTI (Filtek Supreme XTE: incremental technique); XTB (Filtek Supreme XTE: single fill technique); TBF (Tetric Bulk Fill); SF (SonicFill).

\section{Results}

Polymerization Shrinkage Analysis by $\mu C T$

The results for $\mu \mathrm{CT}$ were expressed in percentage volume of polymerization shrinkage (VS). For the volume of polymerization shrinkage, a statistically significant difference was observed between the XTI and XTB groups $(p=0.03)$ and the SF and XTB groups ( $p=0.012)$ (Fig. 3).

\section{Resin-Dentin Bond Strength Analysis by Microtensile bond strenght}

The microtensile test showed a statistically significant difference in the bond strength of the studied groups $(p<0.001)$. The XTI differed statistically significantly from all of the other groups in bond strength $(p<0.001)$. Also, the SF differed statistically from the XTB ( $p=0.049)$. (Table 2$)$.

Fewer pre-test failures were observed in the XTI group. A predominance of adhesive and mixed failures was observed in all of the evaluated groups (Table 2). The values of $\mu$ TBS ranged from $0 \mathrm{MPa}$ (pre-test failure - Ptf) to $68.3 \mathrm{MPa}$. There was a statistically significant difference for the $\mu \mathrm{TBS}$ values when the pre-test failures with zero value $(p<0.001)$ were considered, but this statistical difference was not observed when these specimens were excluded from the analysis $(p=0.50)$.

\section{Correlation Between Shrinkage Volume and Bond Strength}

A statistically significant correlation was not observed between bond strength and shrinkage volume $(p=0.21)$, with a weak negative association ( $r=-0.239)$ (Fig. 4). Regarding the relationship between the bond strength and the number of specimens, the number of specimens obtained in the samples had a significant association with the bond strength in the group that considered the pre-test failures $(p<0.001)$. Each specimen had an increase of 2.37

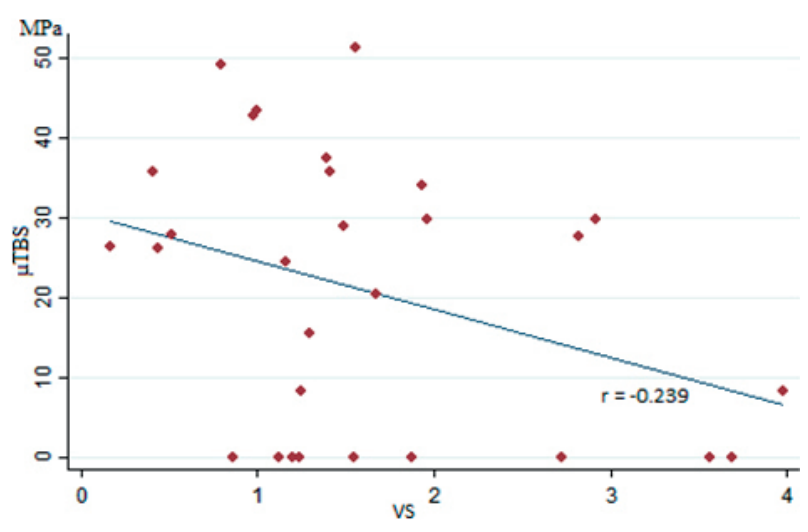

Figure 4. Linear correlation between microtensile bond strength and volumetric shrinkage. VS: volumetric shrinkage. TBS: tensile bond strength. 
$\mathrm{MPa}$ in bond strength.

\section{Discussion}

The appeal of simplifying procedures in clinical practice and the accelerated development of the single insertion of bulk fill composites confront the use of the already established incremental technique in conventional composites. The results of this study verified that the incremental insertion technique (XTI) and the sonic bulk fill technique (SF) presented lower volumes of PS and higher bond strength than the single insertion of conventional composite (XTB), but no correlation was found between these two factors. Thus, hypotheses I and II were rejected because there were significant differences in the polymerization shrinkage and bond strength of the bulk fill and conventional composite types. And the hypothesis III was not rejected because there was any correlation between the volume of PS and bond strength.

The determination of the VS was verified by means of $\mu \mathrm{CT}$, a method recently shown in the literature as being efficient (10), because it allows for better distribution of the dimension of the spaces along the walls in a 3D visualization. The $\mu C T$ can be used effectively to characterize the volume of composites before and after the polymerization, thus allowing the determination of the shrinkages $(9,14)$, with the advantage of not destroying or promoting the induction of forces over the test body (10). In addition, the evaluation by $\mu \mathrm{CT}$ can produce quantitative analyses of the PS -compared to the conventional methods, which are qualitative or semi-quantitative (14) -which are fundamental for determining the volume of shrinkage.

The results of this study demonstrate a statistically significant difference for the \%VS after the polymerization. The SF group presented lower shrinkage, followed by the (XTI), TBF, and XTB groups (Fig. 3). Conventional nanoparticulate composites, such as the one used in this study, were introduced for their improved mechanical properties and reduced shrinkage, which explains the low observed shrinkage for the XTI. The highest VS value being found for the XTB is explained by the modification of the recommended technique $(1.5 \mathrm{~mm})$. For this material, the manufacturer does not indicate single insertions $(4 \mathrm{~mm})$, since insufficient polymerization in deeper portions of the material can compromise its physical properties.

Some factors may have contributed to the studied bulk fill composites presenting a low PS. According to the literature (15), the magnitude of the composite's shrinkage is controlled by the material's composition. An increase in the loaded content may, until a certain point, reduce the polymerization shrinkage by decreasing the monomer content in relation to the charge/monomer. Also, the low shrinkage in the TBF group may be due to the changes in the organic matrix. According to the manufacturer, TBF increases the polymerization depth through the insertion of a new initiator (Ivocerin ${ }^{\circledR}$ ), which, along with the camphorquinone/amine present in the composites, allow suitable polymerization, even in higher increments (16), still, the presence of prepolymerized particles of TBF can decrease the polymerization shrinkage.

This study's results verify a statistically significant difference of bulk fill and conventional composites $(p<0.001)$ using $\mu$ TBS. The evaluation of the restorations in deep cavities and with a high $\mathrm{C}$-factor $(\mathrm{C}=4.2)$ was intended to verify the behavior of these materials after a possible shrinkage stress in the walls of the cavity and its impact on the bond strength. Generally, the bond strength is lower in deep cavity preparations when compared to the insertion of the material on flat surfaces (17). Other studies have shown that bond strength is greatly impacted by the cavity configuration factor (18) and by different types of bulk fill composites (13).

The XTI composite showed higher bond strength values when compared to the XTB and bulk fill composites when considered pre-test failures $(p<0.001)$ (Table 2). Likewise, Colak et al. (19) found higher bond strength in a conventional composite that was incrementally

Table 2. Medians and interquartile ranges of $\mu \mathrm{TBS}$

\begin{tabular}{lcccc}
\hline Group & $\mu$ TBS - ptf $(\mathrm{MPa})$ median/IQR & $\mathrm{ptf} / \mathrm{n}$ & $\mu \mathrm{TBS}+\mathrm{ptf}(\mathrm{MPa})$ median/IQR & Failure Analysis (\%) \\
\hline XTI & $27.7 / 2.8^{\mathrm{aA}}$ & $19 / 67$ & $20.3 / 9^{\mathrm{aB}}$ & A: $54 \mathrm{M}: 30 \mathrm{C}: 16$ \\
XTB & $29.7 / 27.6^{\mathrm{aA}}$ & $64 / 67$ & $0 / 0^{\mathrm{cB}}$ & A: $33 \mathrm{M}: 67$ \\
TBF & $35.8 / 7.7^{\mathrm{aA}}$ & $56 / 71$ & $4 / 7.6^{\mathrm{bcB}}$ & A: $26.7 \mathrm{M}: 60 \mathrm{C}: 13.3$ \\
SF & $24.5 / 13.4^{\mathrm{aA}}$ & $52 / 72$ & $5.4 / 8.5^{\mathrm{bB}}$ & A: $26.7 \mathrm{M}: 60 \mathrm{C}: 13.3$ \\
\hline
\end{tabular}

XTI: Filtek Supreme XTE (incremental technique). XTB: Filtek Supreme XTE (single fill technique. TBF: Tetric Bulk Fill; SF: SonicFill. SD: standard deviation; "-ptf" = without considering pre-test failures; "+ptf" = $0 \mathrm{MPa}$ considering pre-test failures; $\mathrm{n}=$ number of specimens; IQR: Interquartile Ranges; A: adhesive; M: mixed; C: cohesive. Means followed by different letters differ from each other, columns to lowercase (Kruskal Wallis, $\mathrm{p}<0.01$ ), rows to uppercase (Mann Whitney, $\mathrm{p}<0.05$ ). 
inserted than in bulk fill composites TBF and SF. Still, the bulk fill composites presented higher bond strength than the XTB, corroborating with the literature $(6,17)$. When the incremental and bulk fill techniques were compared, regardless of composites, better results were found for the incremental technique (3).

In the $\mu$ TBS study, one of the important factors to be evaluated is the number of pre-test failures (20). Not considering pre-test failures values could lead to a more misleading interpretation than when we consider them, for example the XTB group had only 3 specimens for $\mu \mathrm{TBS}$, however 3 specimens cannot represent a universe of 67. Like this, a value of $0 \mathrm{MPa}$ was assigned for pre-test failures because doing so is a widely accepted method in the literature $(11,13,20)$. This actually penalized the material seriously because there was always a certain bond strength above $0 \mathrm{MPa}$. However, if the specimens that failed before testing would have been excluded from the $\mu$ TBS calculation, distinctly a higher data would have been noted, as in the XTB group.

The results of this study showed that there was a statistically significant difference between the groups when the values of the pretested lost specimens were considered to be 0, (Table 2). Likewise, Van Ende et al. (13) observed higher values for the bond strength of the Surefil SDR composite, which did not present pre-test failures among the specimens submitted to microtensile testing in Class I cavities. Differently, other bulk fill and conventional composites showed low bond strength values, because they had more pre-test failures. Different results can be obtained when not considering pre-test failures, such as a study (4) that found greater results for the bond strength of a BFC when compared to conventional composites. The $\mu \mathrm{CT}$ methodology used in this study was fundamental to analyzing, in 3D, that pre-test failures can be associated not only with the cutting technique and specimen preparation but also with bad adaptation of materials during the insertion/condensation of the composites in the cavity before polymerization. This demonstrates the high variability in bond strength results and emphasizes the need for further investigation (13).

According to Table 2, it was observed that the XTB group did not show cohesive failure. It was observed that when the incremental or bulk fill technique was correctly used, some cohesive failures could be find, corroborating the hypothesis that when the techniques are used properly there is a better bonding of the dentin/material. In the microtensile test, due to the small area tested, there is a greater representativeness of adhesive and/or mixed failures (18). Despite proper curing of the composite itself, the oxygen-inhibited layer of the adhesive may not receive sufficient energy to copolymerize adequately with the overlying composite, creating a fragile zone at the interface, which may explain the occurrence of adhesive failures in cavities (13).

The correlation analysis between the PS in $\mu \mathrm{CT}$ and $\mu \mathrm{TBS}$ in bulk fill composites for posterior class I restorations with a high C-factor was not significant, although there were differences in the isolated PS values and bond strength of the studied composites (Fig. 4). Guo et al. (21) observed that in the composites, the bond strength during the polymerization time follows a similar tendency to stress/ shrinkage tension, with the bond strength decreasing as the composite's thickness increases due to reduced irradiance at the tooth/composite interface. Importantly, in addition to the PS, the type of adhesive system $(6,11)$ and other factors may influence the bond strength (18).

Areas suggestive of gaps in the dentin wall of the cavity before polymerization (Fig. 2) raises doubts about whether pre-test failures are exclusively caused by polymerization shrinkage. Sagsoz et al. (4) observed satisfactory results of $\mu$ TBS for bulk fill composites; however, studies that evaluate the bond strength without observing the marginal adaptation before and after polymerization may not be reliable. The preparation of the specimens to evaluate the $\mu \mathrm{TBS}$, as well as the preparation to observe the tooth/ composite interface in scanning electronic microscopy (7), can generate stresses and cracks in the test body. Differently, the images obtained by $\mu \mathrm{CT}$ can be used to analyze the same sample several times without deteriorating or changing test body's structure (7).

The weak correlation between the volume of the shrinkage and the bond strength $(r=-0.2399)$ confirms the premise that the composites contract towards the walls that are bonded (22) and not, as believed before that the composites contracted in a direction toward the light $(23,24)$. Thus, the interface may rupture if the shrinkage stress (24), between 13 and $17 \mathrm{MPa}$, is higher than the bond strength between the composite and the adhesive system, resulting in cracks (24). The obtained results verify that the bond strength, when not considering the pre-test failures, ranged from 24.6 to $34.0 \mathrm{MPa}$, higher than the values indicated by Davisson et al. (24); that is, the nonpolymerization shrinkage was able to interfere with the bond strength.

Within the limits of this study, it was concluded that the bulk fill composites type presents a polymerization shrinkage similar to that of the conventional nanoparticulate composite inserted using the incremental technique. The bond strength was higher for the composite incrementally inserted, which presented a lower number of pretest failures when compared to bulk fill composites. No correlation was observed between the volume of polymerization shrinkage and the bond strength of the 
class I restorations with high C-factor when bulk fill and conventional composites were used.

\section{Resumo}

0 presente estudo teve por objetivo avaliar a contração de polimerização (CP) usando microtomografia computadorizada $(\mu C T)$ e a resistência de união por microtração ( $\mu \mathrm{TBS}$ ) em restaurações classe I de compósitos bulk fill (CBF) e convencional, assim como a correlação entre esses fatores. Cavidades classe I ( $4 \times 5 \times 4 \mathrm{~mm})$, fator $C=4,2$, foram feitas em terceiros molares livres de cárie que foram randomizados e divididos em 4 grupos $(\mathrm{n}=6)$ : XTI (Filtek Supreme XTE: técnica incremental); XTB (Filtek Supreme XTE: técnica de preenchimento único); TBF (Tetric Bulk Fill); ESF (SonicFill). Cada dente foi escaneado duas vezes em $\mu \mathrm{CT}$ : T0 -após o preenchimento da cavidade com compósito, e T1 - após a cura à luz. Os dados foram analisados subtraindo o volume do compósito para cada tempo (T1 T0). Após 1 semana, os dentes foram seccionados transversalmente no sentido vestíbulo-palatino e mesio-distal para obter espécimes com aproximadamente $1 \mathrm{~mm}^{2}$ de espessura e fixados em uma máquina de ensaio universal para teste de $\mu$ TBS. Os testes de Kruskal-Wallis e Dunn mostraram diferença estatisticamente significante para a contração em $\mu \mathrm{CT}$ entre XTI e XTB, e entre SF e XTB. Em relação à $\mu$ TBS, todos os grupos diferiram do XTB. Compósitos do tipo bulk fill apresentam uma CP similar ao compósito convencional nanoparticulado inserido usando a técnica incremental, porém a resistência de união foi maior para o grupo incremental, que apresentou um menor número de falhas pré-teste quando comparado aos CBF. Não foi observada correlação entre a contração de polimerização e a resistência de união nos compósitos estudados.

\section{Acknowledgements}

The authors thank FAPEMA (Fundação de Amparo à Pesquisa do Maranhão) for financial support provided for this research (Universal Notice \#40/2016, PAEDT Notice \#16/2015).

\section{References}

1. Sampaio CS, Chiu KJ, Farrokhmanesh E, Janal M, Puppin-Rontani RM, Giannini $M$, et al.. Microcomputed tomography evaluation of polymerization shrinkage of Class I flowable resin composite restorations. Oper Dent 2017;42:16-23.

2. Campos EA, Ardu S, Lefever D, Jassé FF, Bortolotto T, Krejci I. Marginal adaptation of class II cavities restored with bulk-fill composites. J Dent 2014:42:575-581.

3. Kumagai RY, Zeidan LC, Rodrigues JA, Reis AF, Roulet JF. Bond strength of a flowable bulk-fill resin composite in Class II MOD cavities. J Adhes Dent 2015;17:427-432.

4. Sagsoz O, Ilday NO, Karatas O, Cayabatmaz M, Parlak H, Olmez MH, et al.. The bond strength of highly filled flowable composites placed in two different configuration factors. J Conserv Dent 2016;19:21-25.

5. Ferracane JL, Hilton TJ. Polymerization stress - Is it clinically meaningful? Dent Mater 2016;32:1-10.

6. Van Ende A, De Munck J, Van Landuyt KL, Poitevin A, Peumans M, Van Meerbeek B. Bulk-filling of high C-factor posterior cavities: effect on adhesion to cavity-bottom dentin. Dent Mater 2013;29:269-277.

7. Meleo D, Manzon L, Pecci R, Zuppante F, Bedini R. A proposal of microtomography evaluation for restoration interface gaps. Ann Ist Super Sanita 2012;48:83-88

8. Kim HJ, Park SH. Measurement of the internal adaptation of resin composites using micro-CT and its correlation with polymerization shrinkage. Oper Dent 2014;39:57-70.

9. Sun J, Lin-Gibson S. X-ray microcomputed tomography for measuring polymerization shrinkage of polymeric dental composites. Dent Mater 2008;24:228-234.

10. Carrera CA, Lan C, Escobar-Sanabria D, Li Y, Rudney J, Aparicio C, et al.. The use of micro-CT with image segmentation to quantify leakage in dental restorations. Dent Mater 2015;31:382-390.

11. Mine A, De Munck J, Cardoso MV, Van Landuyt KL, Poitevin A, Kuboki T, et al.. Effect of low-shrinking composite on the bonding effectiveness of two adhesives in occlusal Class-I cavities. Dent Mater J 2012;31:418426.

12. Fronza BM, Rueggeberg FA, Braga RR, Mogilevych $B$, Soares LE, Martin $A A$, et al.. Monomer conversion, microhardness, internal marginal adaptation, and shrinkage stress of bulk-fill resin composites. Dent Mater 2015;31:1542-1551.

13. Van Ende A, De Munck J, Van Landuyt K, Van Meerbeek B. Effect of Bulk-filling on the Bonding Efficacy in Occlusal Class I Cavities. J Adhes Dent 2016;18:119-124.

14. Zeiger DN, Sun J, Schumacher GE, Lin-Gibson S. Evaluation of dental composite shrinkage and leakage in extracted teeth using $\mathrm{X}$-ray microcomputed tomography. Dent Mater 2009;25:1213-1220.

15. Al Sunbul H, Silikas N, Watts DC. Polymerization shrinkage kinetics and shrinkage-stress in dental resin-composites. Dent Mater 2016;32:9981006.

16. Ilie N, Bucuta S, Draenert M. Bulk fill resin based composites: an in vitro assessment of their mechanical performance. Oper Dent 2013;38:618 625.

17. Armstrong SR, Keller JC, Boyer DB. The influence of water storage and $\mathrm{C}$-factor on the dentin-resin composite microtensile bond strength and debond pathway utilizing a filled and unfilled adhesive resin. Dent Mater 2001;17:268-276.

18. Van Ende A, De Munck J, Mine A, Lambrechts P, Van Meerbeek B. Does a low-shrinking composite induce less stress at the adhesive interface? Dent Mater 2010;26:215-222.

19. Colak $H_{1}$ Ercan $E_{1}$ Hamidi MM. Shear bond strength of bulk-fill and nano-restorative materials to dentin. Eur J Dent 2016:10:40-45.

20. Armstrong $S$, Breschi L, Özcan M, Pfefferkorn F, Ferrari M, Van Meerbeek B. Academy of Dental Materials guidance on in vitro testing of dental composite bonding effectiveness to dentin/enamel using micro-tensile bond strength ( $\mu$ TBS) approach. Dent Mater 2017;33:133-143.

21. Guo J, Holmes B, Yang B, Li Y, Heo YC, Chen J, et al.. Determining the temporal development of dentin-composite bond strength during curing. Dent Mater 2016;32:1007-1118.

22. Versluis A, Tantbirojn D, Douglas WH. Do dental composites always shrink toward the light? J Dent Res 1998;77:1435-1445

23. Lutz F, Kejci I, Luescher B, Oldenburg TR. Improved proximal marginal adaptation of class II composite restorations by use of light reflecting wedges. Quintessence Int 1986;17:659-664.

24. Davidson $\mathrm{CL}$, de Gee AJ, Feilzer A. The competition between the composite dentin bond strength and the polymerization contraction stress. J Dent Res 1984;63:1396-1399.

Received November 24, 2017 Accepted January 15, 2018 